\title{
EFFECTS OF POSTNATAL UNDERNUTRITION ON THE CATECHOLAMINE AND SEROTONIN CONTENTS OF SUCKLING RAT BRAIN
}

\author{
Keiko HisATOMI and Yoshiaki NiIYAmA ${ }^{1}$ \\ Department of Nutrition, School of Medicine, The University of Tokushima, \\ Tokushima 770, Japan \\ (Received February 9, 1980)
}

\begin{abstract}
Summary The effect of postnatal undernutrition on the catecholamine and serotonin contents of various parts of the brain of suckling rats was examined. Undernourishment was induced by increasing the litter size to 18 pups from day 1 to 21 after birth. In control pups, the total amounts of norepinephrine and dopamine in the whole brain increased greatly during the suckling period (norepinephrine: $17.7 \mathrm{ng}$ at birth, $154 \mathrm{ng}$ on day 10, and $420 \mathrm{ng}$ on day 21; dopamine: $12.6 \mathrm{ng}$ at birth, $269 \mathrm{ng}$ on day 10, and $1,022 \mathrm{ng}$ on day 21). Similar, but less marked increases in the norepinephrine and dopamine contents of the brain were observed in malnourished pups. The norepinephrine contents of the forebrain, cerebellum, and brain stem of malnourished pups were comparable with those of normal pups on day 10 but the contents of the cerebellum and brain stem were significantly less than those of normal pups on day 21 . Postnatal malnutrition also led to a significant decrease in the dopamine content of the forebrain. In contrast, the serotonin content of the brain of undernourished pups was significantly higher than that of controls. The activities of tyrosine hydroxylase in the forebrain and brain stem of control pups at the end of suckling period were significantly higher than those of undernourished pups (forebrain: $18.3 \mathrm{pmol}$ in controls and 11.5 pmol in malnourished pups; brain stem: $12.3 \mathrm{pmol}$ in controls and 9.8 pmol in malnourished pups). The tyrosine hydroxylase activity (pmol/g) correlated more closely with the norepinephrine content than with the dopamine or norepinephrine plus dopamine content. The tyrosine and phenylalanine contents of the brain were similar in the two groups. It is concluded from these findings that the catecholamine content of the brain is regulated by the enzyme activity rather than the levels of precursor amino acids.
\end{abstract}

Keywords brain catecholamine (CA), serotonin, tyrosine hydroxylase, early postnatal malnutrition, lactation, brain free amino acids

1 久富啓子, 新山喜昭 
The brain of rats grows rapidly just after birth and nutritional deficiency during this critical period results in morphological or maturational growth retardation of the brain, although this is less pronounced than retardation of somatic growth (1-5). Moreover, there is evidence that the normal growth rate and the growth response to malnutrition differ in different regions of the brain (6).

Aminergic neurons are located in particular regions of the brain and are involved in a variety of physiological functions. Loizou and Salt (7) suggested that the increases in monoamine concentrations in the brain during development result from proliferation of axon terminals. Ontogenetic increases in brain monoamines are greater in the early postnatal period than in utero, suggesting that growth and maturation of the central aminergic system are mainly postnatal events $(8-12)$.

The influences of early postnatal undernutrition on the norepinephrine, dopamine, and serotonin contents of rat brain have been studied by many investigators $(11,13-15)$, but results have not been consistent. Therefore, we examined the effects of undernutrition on the monoamine contents of different regions of the brain of suckling rats and studied their correlation with changes in precursor amino acids and tyrosine hydroxylase activity.

\section{MATERIALS AND METHODS}

Virgin rats of the Sprague-Dawley strain, weighing about $160 \mathrm{~g}$, were obtained commercially, and were fed a $20 \%$ casein diet until they weighed about $190 \mathrm{~g}$. Then they were mated with males of the same strain. Pregnant rats were given the $20 \%$ casein diet ad libitum to term. The time of delivery was checked daily. All litters were born on day 21 or 22 of pregnancy. At birth the litter size was adjusted to 6 or 18 pups by removing or adding pups born on the same day.

The food intake of lactating dams and the body weights of the dams and pups were measured daily.

On days 1, 10, and 21 of age, suckling pups of each group were killed by decapitation. The brains were removed quickly and separated into three regions, forebrain, cerebellum, and other parts. All tissues were frozen on dry ice and stored at $-70^{\circ} \mathrm{C}$ until analysis.

Norepinephrine (NE) and dopamine (DA) were determined by the radioenzymic assay described by Engelman et al. (16) with slight modification. NE and DA in the deproteinized brain supernatant were converted to their $o$-methylated derivatives by COMT in the presence of ${ }^{3} \mathrm{H}$-S-adenosylmethionine and the radioactivities in the resulting labelled $o$-methylated compounds were measured after separation of the various compounds on a silica plate developed with chloroform : ethyl ether: ethylamine $(16: 3: 2$, by vol.) (17).

Serotonin (5-HT) and 5-hydroxyindole acetic acid (5-HIAA) in the brain were measured fluorometrically (18).

Tyrosine hydroxylase was assayed radiometrically by the procedure of Croll et al. (19), which involves the conversion of ${ }^{3} \mathrm{H}$-tyrosine via ${ }^{3} \mathrm{H}$-DOPA to ${ }^{3} \mathrm{H}$-DA in 
the presence of aromatic L-amino acid decarboxylase. The ${ }^{3} \mathrm{H}-\mathrm{DA}$ was selectively extracted into 3-heptanone as a complex with Kalignost (sodium tetraphenylborate), and was counted in a scintillation spectrometer.

DNA in the brain was measured spectrophotometrically (20). Protein was determined by the method of Lowry et al.(21) in the solution obtained by hydrolysis with $0.3 \mathrm{~N} \mathrm{KOH}$ during DNA determination. Free amino acids in the brain and plasma were determined with an automatic amino acid analyzer.

\section{RESULTS}

Food intake of dams and changes in body weight of dams and pups

In the 20-day lactation period the total food intakes of dams rearing 6 and 18 pups were 511 and $639 \mathrm{~g}$, respectively (Table 1). Although the dams nursing 18 pups ate significantly more food than the control dams, their body weight decreased slightly during lactation.

Changes in body weight of the suckling pups are shown in Table 1. The body weight of control pups increased rapidly from $5.3 \mathrm{~g}$ at birth to $38.4 \mathrm{~g}$ on day 21 , while that of malnourished pups increased less. The differences in body weight of the two groups became significant after day 4 of suckling and the body weight of malnourished pups was only $60 \%$ that of the controls on day 21 .

Organ weight, carcass composition, and day when eyes opened

The organ weights of normal and malnourished suckling rats are shown in Table 2. On days 10 and 21, the respective organ weights of the malnourished pups were significantly less than those of the controls. The weights of the forebrain,

Table 1. Food intake of dams and changes in body weight of dams and their pups during lactation.

\begin{tabular}{|c|c|c|c|c|c|c|c|}
\hline \multirow{2}{*}{ Group } & \multirow{2}{*}{$\begin{array}{c}\text { Food } \\
\text { intake } \\
\text { (g/20 days) }\end{array}$} & \multicolumn{3}{|c|}{$\begin{array}{c}\text { Body weight of dams } \\
\text { on day }\end{array}$} & \multicolumn{3}{|c|}{$\begin{array}{l}\text { Body weight of pups } \\
\text { on day }\end{array}$} \\
\hline & & 1 & $\begin{array}{l}10 \\
(\mathrm{~g})\end{array}$ & 21 & 1 & $\begin{array}{l}10 \\
(\mathrm{~g})\end{array}$ & 21 \\
\hline 6-pup group & $\begin{array}{c}511 \pm 62^{\mathrm{a}} \\
(5)^{\mathrm{b}}\end{array}$ & $236 \pm 6$ & $234 \pm 15$ & $235 \pm 12$ & $\begin{array}{c}5.3 \pm 0.3 \\
(30)\end{array}$ & $16.9 \pm 2.4$ & $38.4 \pm 4.5$ \\
\hline 18-pup group & $\frac{639 \pm 92}{(5)}$ & $229 \pm 6$ & $221 \pm 13$ & $213 \pm 12$ & $\begin{array}{c}5.6 \pm 0.7 \\
(69)\end{array}$ & $12.0 \pm 1.8$ & c $22.5 \pm 3.3^{c}$ \\
\hline
\end{tabular}

${ }^{a}$ Means $\pm \mathrm{SD}$. ${ }^{\mathrm{b}}$ Figures in parentheses represent numbers of rats. ${ }^{\mathrm{c}}$ Significantly different from value of control group at the level of $0.1 \%$. 


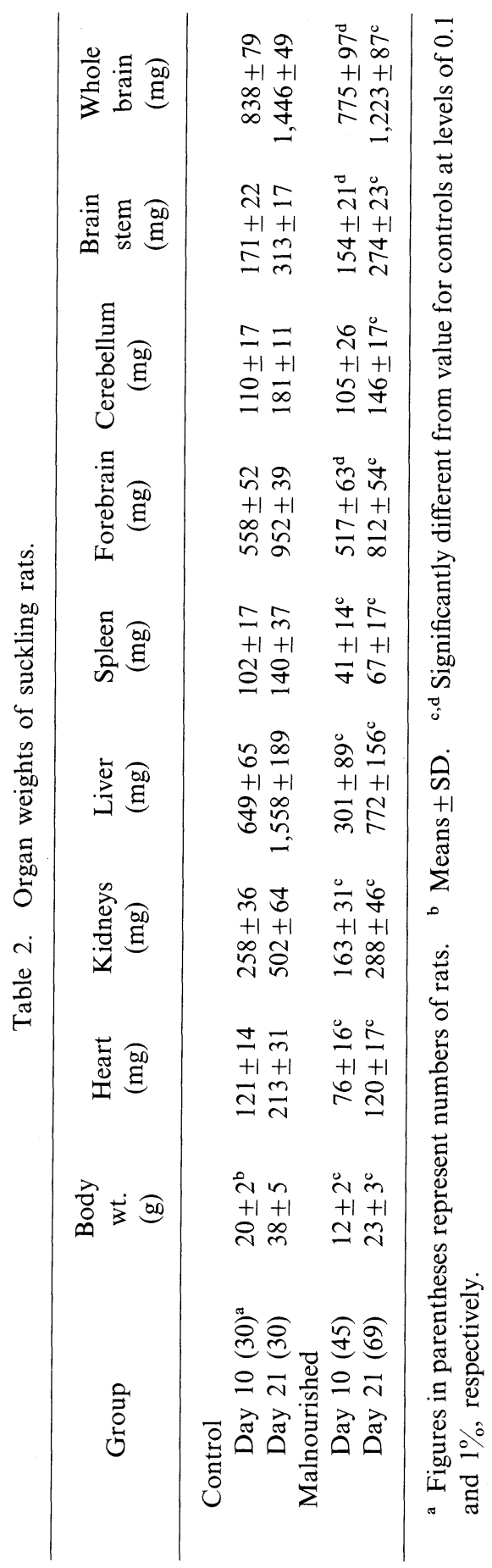


cerebellum, and brain stem of malnourished pups were also significantly less, except for that of cerebellum on day 10 .

Analyses of the water, nitrogen and fat contents of the carcass showed that malnourished pups had a higher water content and lower protein and fat contents than control pups on days 10 and 21 (data not shown). These findings indicate that the deprived animals were chemically immature.

In addition to physical and biochemical growth retardation, functional impairment was also seen in the malnourished group; for example, the eyes of malnourished pups opened on day 18, whereas those of controls opened on day 16 .

\section{Protein and nucleic acid contents of suckling rat brain}

Table 3 shows the protein and DNA contents of suckling rat brains. In the well-nourished group, the total DNA content increased appreciably in all regions during suckling. The DNA contents of the forebrain, cerebellum, and brain stem on day 21 were, respectively, 2.3, 16, and 3.4 times higher than those at birth (22). Proliferation of cerebellar cells was associated with increases in both cell density (DNA concentration) and tissue mass (cerebellar weight). The total DNA contents of all regions of the brain of undernourished pups also increased ontogenetically, but significantly less than in controls.

During the suckling period the total amounts of protein in the respective regions of the brain increased greatly, irrespective of the nutritional status of the pups. The protein concentrations in all regions of the brain were still at the neonatal levels on day 10 , but then they increased significantly, suggesting that hypertrophy of the brain cells occurs mainly after day 10 .

Changes in serotonin and 5-hydroxyindole acetic acid contents of suckling rat brains In control pups, the total amount of 5-HT in the whole brain increased rapidly in the early postnatal period and thereafter remained unchanged (Table 4). Undernourishment during suckling resulted in increased concentrations and total contents of 5-HT in the whole brain and in different regions of the brain. In both groups, the total amount of 5-HIAA in the whole brain increased markedly throughout the suckling period. The respective amounts of 5-HIAA in various regions of the brain on days 10 and 21 were similar in control and malnourished pups except that the amount in the forebrain on day 10 was less in malnourished pups.

Regional changes in norepinephrine, dopamine, and tyrosine hydroxylase in suckling rat brain

The NE and DA contents and TH activity in rat brain on days 10 and 21 after birth are shown in Table 5. As reported previously, the concentrations and total amounts of NE in the forebrain, cerebellum, and brain stem of neonates were 70 , 92, and $130 \mathrm{pg} / \mathrm{mg}$ and 7.73, 2.96, and $7.04 \mathrm{ng}$, respectively (22). Since both the concentration of NE and the tissue mass increased, the total amounts of NE in the 


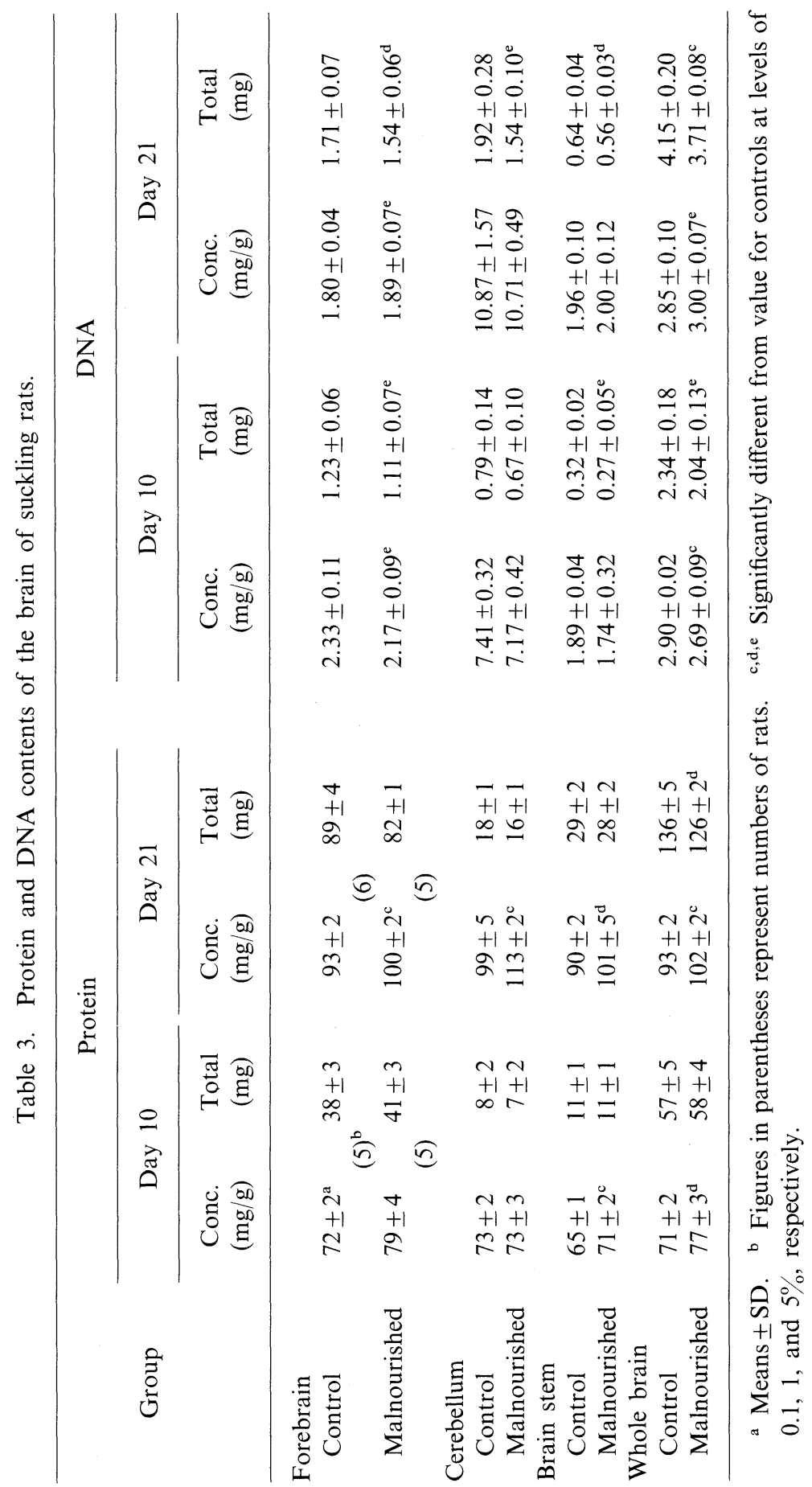




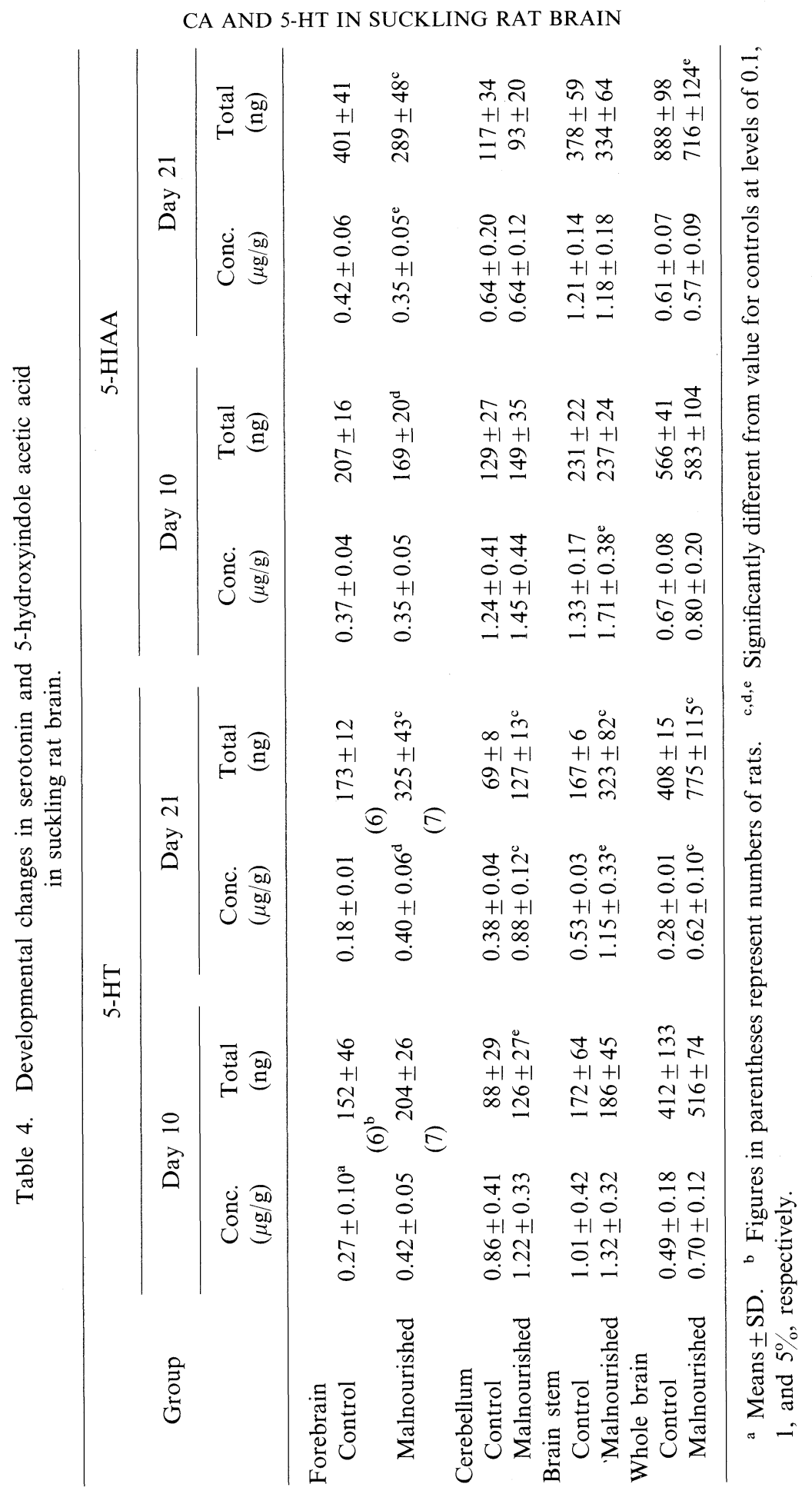

Vol. 26, No. 3, 1980 


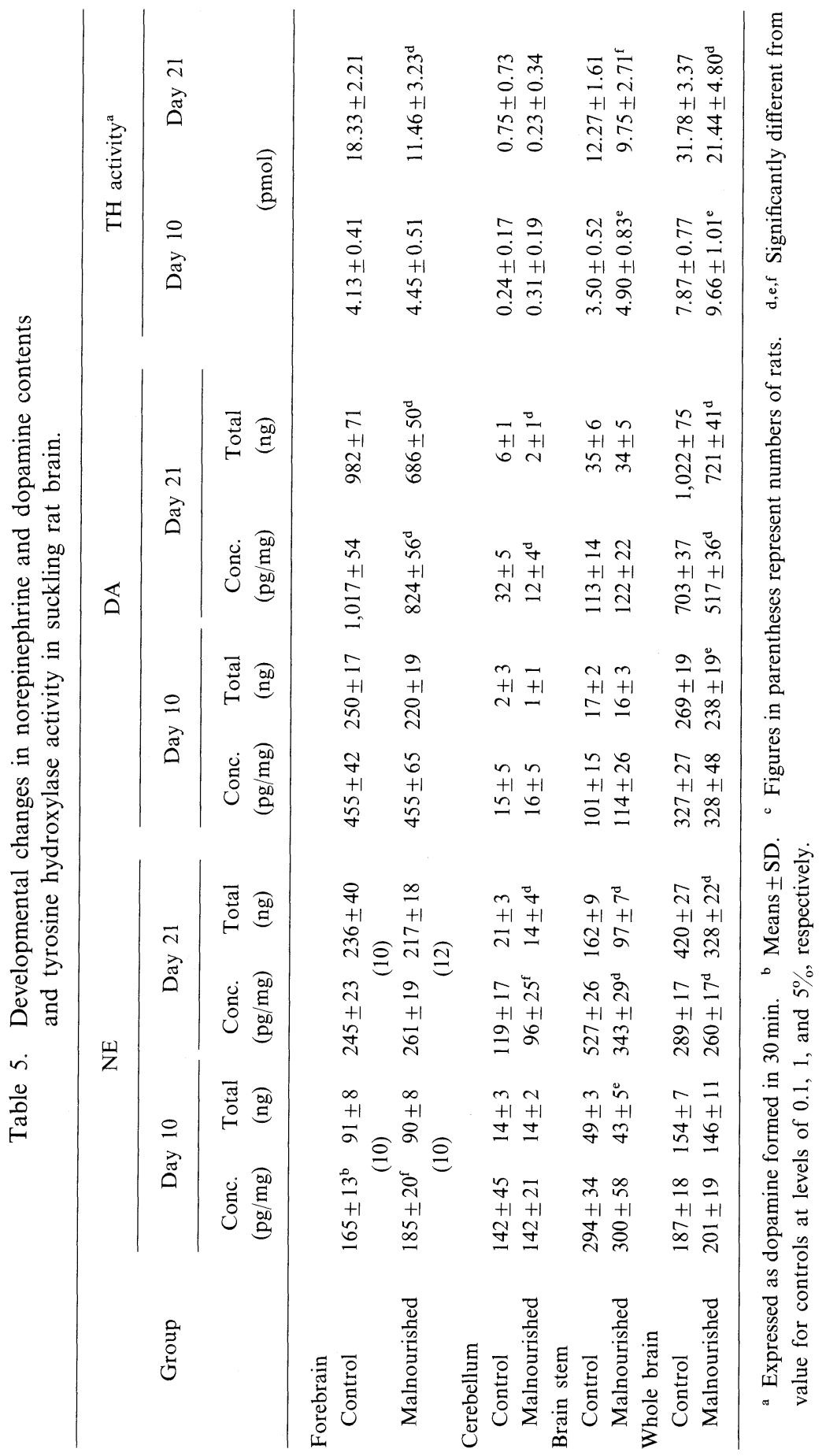


brain stem and forebrain of control pups increased greatly in the early postnatal period. In undernourished rats changes in the NE contents of these regions of the brain were similar to those in controls, but the content in the brain stem was lower on day 21.

At birth the concentrations of DA ( $\mathrm{pg} / \mathrm{mg})$ in the forebrain, cerebellum, and brain stem are 69,70 , and 49 , respectively, and the total amounts (ng) are 7.63, 2.27 , and 2.67, respectively (22). Both the concentration and the total amount of DA increased greatly in the forebrain of normal pups during suckling: on day 21 the total amount was $982 \mathrm{ng}$, constituting $96 \%$ of that in the whole brain, and representing about 130 times the amount on day 1. A similar, but less marked ontogenetic change in the DA content of the forebrain was seen in undernourished pups. In both groups, the postnatal increase in the DA content of the brain stem was moderate, and that in the cerebellum was very slight.

The total activities of $\mathrm{TH}$, expressed as pg of dopamine formed for $30 \mathrm{~min}$, in the forebrain, cerebellum, and brain stem of normal neonates were found to be $0.62,0.43$, and 0.39 , respectively (22). On day 21 of life, the total activities in the forebrain and brain stem were about 30 -fold those at birth, reflecting high NE or DA contents in these regions. On the contrary, the activity in the cerebellum was very low and showed no ontogenetic change. In undernourished pups the TH activities in the forebrain and brain stem also increased ontogenetically, but on day 21 they were significantly less than in controls.

\section{Free amino acid concentrations in the plasma and brain of pups}

The free amino acid concentrations in the plasma and whole brain of normal and malnourished suckling rats are shown in Table 6. The patterns of free amino acids in the plasma and brain of the undernourished animals were normal, except for relative increases in glycine in the plasma and brain and glutamic acid in the brain. The plasma levels of all individual amino acids except glycine in the malnourished pups were comparable to, or lower than those in control animals. The patterns and concentrations of free amino acids in the brain were similar in the two groups. The concentrations of tyrosine in the brains of normal and malnourished pups were 110 and $124 \mu \mathrm{mol} / \mathrm{kg}$, respectively.

\section{DISCUSSION}

In the present investigation early undernutrition was induced by increasing the litter size to 18 pups. On day 21 of life, the body and organ weights of these malnourished pups were significantly less than those of controls, and the pups were chemically immature judging from their water, fat, and protein contents. Although it has been established that developing brain is highly resistant to maternal malnutrition during gestation and/or suckling (23-25), the brain of our malnourished pups showed considerable growth impairment, indicating that the pups were severely undernourished.

Vol. 26, No. 3, 1980 
Table 6. Free amino acid concentrations in the plasma and brain of pups.

\begin{tabular}{lccccc}
\hline & \multicolumn{2}{c}{ Plasma $(\mu \mathrm{mol} /$ liter $)$} & & \multicolumn{2}{c}{ Brain $(\mu \mathrm{mol} / \mathrm{kg})$} \\
\cline { 2 - 3 } \cline { 5 - 6 } & Control & Malnourished & & Control & Malnourished \\
\hline Lys & $(3)^{\mathrm{a}}$ & $(3)$ & & $(4)$ & $(4)$ \\
Thr & $494 \pm 150^{\mathrm{b}}$ & $376 \pm 24$ & & $346 \pm 112$ & $300 \pm 84$ \\
Met & $421 \pm 24$ & $327 \pm 39^{\mathrm{d}}$ & & $1,093 \pm 197$ & $1,098 \pm 29$ \\
Val & $52 \pm 9$ & $38 \pm 8$ & & $222 \pm 59$ & $228 \pm 91$ \\
Ile & $221 \pm 38$ & $170 \pm 18$ & & $125 \pm 29$ & $100 \pm 13$ \\
Leu & $114 \pm 13$ & $85 \pm 8^{\mathrm{d}}$ & & $65 \pm 22$ & $43 \pm 12$ \\
Phe & $186 \pm 19$ & $135 \pm 16^{\mathrm{d}}$ & & $141 \pm 82$ & $84 \pm 9$ \\
EAA & $68 \pm 3$ & $60 \pm 14$ & & $82 \pm 19$ & $66 \pm 19$ \\
Asp & $1,556 \pm 220$ & $1,190 \pm 91$ & & $2,075 \pm 48$ & $1,918 \pm 59$ \\
Glu & $35 \pm 4$ & $30 \pm 11$ & & $5,910 \pm 1,262$ & $3,992 \pm 908^{\mathrm{d}}$ \\
Ser & $162 \pm 11$ & $125 \pm 42$ & & $11,437 \pm 1,094$ & $12,024 \pm 3,110$ \\
Gly & $599 \pm 69$ & $467 \pm 96$ & & $1,622 \pm 159$ & $1,696 \pm 202$ \\
Ala & $298 \pm 49$ & $362 \pm 44$ & & $1,158 \pm 51$ & $1,076 \pm 53$ \\
Cys & $547 \pm 78$ & $402 \pm 71$ & & $890 \pm 99$ & $903 \pm 59$ \\
Tyr & $11 \pm 2$ & $11 \pm 1$ & & $24 \pm 8$ & $47 \pm 21$ \\
His & $138 \pm 31$ & $106 \pm 30$ & & $110 \pm 28$ & $124 \pm 27$ \\
Arg & $113 \pm 5$ & $79 \pm 13^{\mathrm{d}}$ & & $124 \pm 30$ & $103 \pm 10$ \\
NEAA & $289 \pm 16$ & $214 \pm 10^{\mathrm{c}}$ & & $135 \pm 27$ & $101 \pm 25$ \\
Nyynnn & $2,193 \pm 219$ & $1,796 \pm 262$ & & $21,410 \pm 2,340$ & $20,065 \pm 3,891$ \\
\hline
\end{tabular}

${ }^{a}$ Figures in parentheses represent numbers of rats. ${ }^{b}$ Means \pm SD. ${ }^{c, d}$ Significantly different from value for controls at levels of 1 and $5 \%$, respectively. ${ }^{\mathrm{e}}$ Essential amino acids. ${ }^{\mathrm{f}}$ Nonessential amino acids.

Measurements of the weights and total DNA contents of different parts of the brain indicated regional differences in growth retardation in malnourished pups, the cerebellum being the most affected. This may be because proliferation of neuronal cells occurs mainly before birth in the forebrain and brain stem, but after birth in the cerebellum (2).

Neurotransmitter amines in the central nervous system are present in specific aminergic neurons which are located in particular regions of the brain. Since regional differences are seen in growth retardation of the brain in undernourished rats $(6)$, it seemed to be interesting to examine whether specific neurons are affected by malnutrition. Previously we reported that the catecholamine content of normal fetal brain increased from $21 \mathrm{ng}$ on day 18 of gestation to $52 \mathrm{ng}$ at birth (22). However, there are many reports that the monoamine content of developing brain increased far more rapidly just after birth than before birth. Loizou(26), for 
example, reported that the levels of brain NE, DA, and 5-HT increased rapidly in the first 4 to 5 weeks after birth, although the pattern of increase varied in different regions of the brain. He also showed that the increases in these amines were correlated with morphological growth observed by a histochemical fluorescent technique. Our results on the changes in brain monoamines of normal pups during development are in accord with those of other investigators.

As mentioned above, the suckling period is a critical period for development of aminergic neurons: in other words, malnutrition in this stage may have a marked effect on growth of these neurons. The combined effects of prenatal and early postnatal undernutrition on brain monoamine contents were investigated by several workers, but the results obtained were conflicting. Stern et al. (11) examined the ontogenetic changes of 5-HT, 5-HIAA, and NE in normal and proteinmalnourished rats from birth to 300 days of age and found significantly elevated brain levels of monoamines and 5-HIAA in the undernourished group. On the contrary, Sereni et al. (27) observed a reduction of the CA level in the brain of undernourished rats. Ramanamurthy (15) also examined the developmental changes in brain monoamines in normal and undernourished pups from birth to 35 days of age and concluded that there was no difference between the two for 7 days after birth, but that from day 14 the malnourished group showed significantly lower levels of these monoamines. Shoemaker and Wurtman (13) did not detect any change in brain catecholamine concentration in undernourished rats, but found that the total amounts of NE and DA were low because the brain weight was reduced. Ahmad and Rahman (14) could not detect any effect of malnutrition on brain transmitter amines in 42-day-old rats. In the present study, the levels of $\mathrm{NE}$ and DA in different regions of the brain of control and undernourished pups were comparable on days 10 and 21 , except that the NE concentrations in the cerebellum and brain stem of malnourished pups were lower on day 21. Our results are similar to those of Ramanamurthy, though the changes were less marked, probably because our animals were undernourished only during the suckling period, not during gestation and the suckling period.

Unlike the levels of CAs, the level of 5-HT in the brain of undernourished pups was significantly higher than that in controls, in accord with the result of Stern et al. (11).

Finally, the lower levels of CAs in the brain of malnourished pups should be considered in relation to the concentration of precursor amino acids and the activity of the rate-limiting hydroxylating enzyme. As shown in Table 6, the concentrations of free tyrosine and phenylalanine in normal and malnourished pup brains were identical, indicating that reduced levels of brain CAs, if any, were not due to a decrease in the precursor pool size. On the other hand, there was a highly significant correlation between TH activity and NE concentration as seen in Fig. 1; the correlations between $\mathrm{TH}$ activity $(Y, \mathrm{pmol} / \mathrm{g})$ and DA and $\mathrm{NE}+\mathrm{DA}$ were less significant. The regression equations are as follows: 


$$
\begin{array}{ll}
Y=0.0825 X-0.9366 & n=27, r=+0.88,(p<0.001) X=\mathrm{NE}(\mathrm{ng} / \mathrm{g}) \\
Y=0.0127 X+8.892 & n=27, r=+0.52,(p<0.01) X=\mathrm{NE}+\mathrm{DA}(\mathrm{ng} / \mathrm{g}) \\
Y=0.0099 X+12.02 & n=27, r=+0.34,(\mathrm{~ns}) X=\mathrm{DA}(\mathrm{ng} / \mathrm{g})
\end{array}
$$

Porcher and Heller(28), Bacopoulos and Bhatnagar(29), and Schmidt and Bhatnagar (30) also found significant correlations between the TH activity and the concentration of NE in various regions of the brain. Thus, from these investigations and the present work we conclude that decreases in NE and DA in the brain of malnourished pups are associated with a decrease in $\mathrm{TH}$ activity and that the brain CA content is primarily regulated by the level of enzyme activity, not by the content of precursor amino acid.

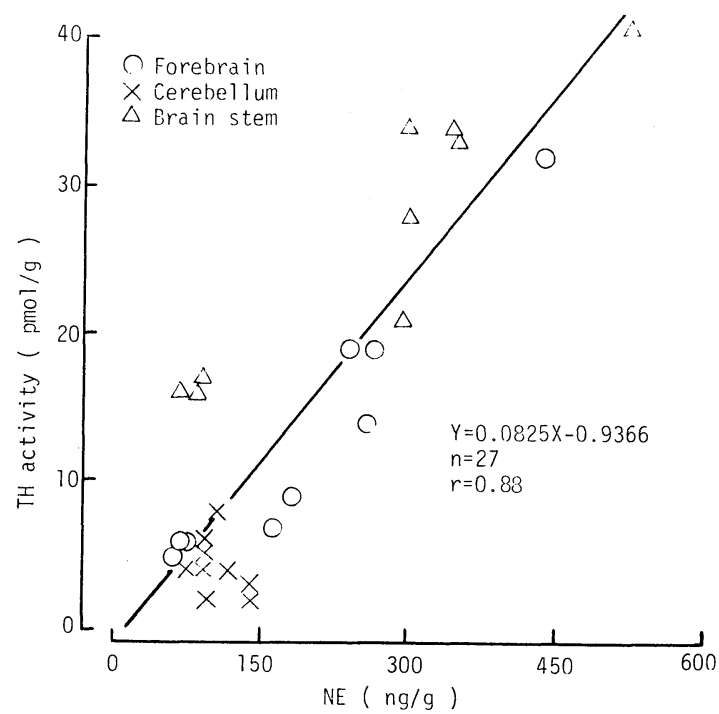

Fig. 1. Relationship between tyrosine hydroxylase activity and norepinephrine content.

\section{REFERENCES}

1) Winick, M., and Noble, A. (1966): Cellular response in rats during malnutrition at various ages. J. Nutr., 89, 300-306.

2) Neville, H. E., and Chase, H. P. (1971): Undernutrition and cerebellar development. Exp. Neurol., 33, 485-495.

3) Salas, M., Diaz, S., and Nieto, A. (1974): Effects of neonatal food deprivation on cortical spines and dendritic development of the rat. Brain Res., 23, 139-144.

4) Cordero, M. E., Diaz, G., and Araya, J. (1976): Neocortex development during severe malnutrition in the rat. Am. J. Clin. Nutr., 29, 358-365.

5) Jones, D. G., and Dyson, S. E. (1976): Synaptic junctions in undernourished rat 
brain-An ultrastructural investigation. Exp. Neurol., 51, 529-535.

6) Winick, M., Brasel, J. A., and Rosso, P. (1972): Nutrition and cell growth, in Current Concepts in Nutrition, Vol. 1, Nutrition and Development, ed. by Winick, M., John Wiley \& Sons, New York, pp. 71-75.

7) Loizou, L. A., and Salt, P. (1970): Regional changes in monoamines of the rat brain during postnatal development. Brain Res., 20, 467-470.

8) Agrawal, H. C., Glisson, S. N., and Himwich, W. A. (1966): Changes in monoamines of rat brain during postnatal ontogeny. Biochim. Biophys. Acta, 130, 511-513.

9) Breese, G. R., and Traylor, T. D. (1972): Developmental characteristics of brain catecholamines and tyrosine hydroxylase in the rat: Effects of 6-hydroxydopamine. Br. J. Pharmacol., 44, 210-222.

10) Coyle, J. T., and Henry, D. (1973): Catecholamines in fetal and newborn rat brain. J. Neurochem., 21, 61-67.

11) Stern, W. C., Miller, M., Forbes, W. B., Morgane, P. J., and Resnick, O. (1975): Ontogeny of the levels of biogenic amines in various parts of the brain and in peripheral tissues in normal and protein malnourished rats. Exp. Neurol., 49, 314-326.

12) Nomura, Y., Naitoh, F., and Segawa, T. (1976): Regional changes in monoamine content and uptake of the rat brain during postnatal development. Brain Res., 101, 305-315.

13) Shoemaker, W. J., and Wurtman, R. J. (1973): Effect of perinatal undernutrition on the metabolism of catecholamines in the rat brain. J. Nutr., 103, 1537-1547.

14) Ahmad, G., and Rahman, M. A. (1975): Effects of undernutrition and protein malnutrition on brain chemistry of rats. J. Nutr., 105, 1090-1103.

15) Ramanamurthy, P. S. V. (1977): Maternal and early postnatal malnutrition and transmitter amines in rat brain. J. Neurochem., 28, 253-254.

16) Engelman, K., Portnoy, B., and Lovenberg, W. (1968): A sensitive and specific double-isotope derivative method for the determination of catecholamines in biological specimens. Am. J. Med. Sci., 255, 259-268.

17) Prada, M. D., and Zürcher, G. (1976): Simultaneous radioenzymatic determination of plasma and tissue adrenaline, noradrenaline and dopamine within the femtomole range. Life Sci., 19, 1161-1174.

18) Kōno, Y. (1974): Fluorometric assay of 5-HT and 5-HIAA. Kurume Med. J., 21, 55-63.

19) Croll, N. E., Lewis, J. P., Reddington, M., Prince, A. K., and Wong, P.T.-H. (1977): Radiometric assay of tyrosine hydroxylase and tryptophan hydroxylase by Kalignost extraction procedures. J. Neurochem., 29, 743-746.

20) Wannemacher, R. W., Jr., Banks, W. L., Jr., and Wunner, W. H. (1965): Use of a single tissue extract to determine cellular protein and nucleic acid concentrations and rate of amino acid incorporation. Anal. Biochem., 11, 320-326.

21) Lowry, O. H., Rosebrough, N. J., Farr, A. L., and Randall, R. J. (1951): Protein measurement with the Folin phenol reagent. J. Biol. Chem., 193, 265-275.

22) Hisatomi, K., Sasaki, S., and Niiyama, Y. (1979): Effect of maternal protein and/or energy deficiency during pregnancy on catecholamines and serotonin in fetal brain. $J$. Nutr. Sci. Vitaminol., 25, 243-253.

23) Zamenhof, S., Van Marthens, E., and Grauel, L. (1971): DNA (cell number) and protein in neonatal rat brain: Alteration by timing of maternal dietary protein restriction. J. Nutr., 101, 1265-1269.

24) Endo, S., Niiyama, Y., Kamori, K., and Inoue, G. (1974): Effect of protein 
deprivation during pregnancy on nucleic acid and protein syntheses in fetal rat brain and liver. Nutr. Rep. Int., 10, 209-219.

25) Zamenhof, S., Hall, S. M., Grauel, L., Van Marthens, E., and Donahue, M. J. (1974): Deprivation of amino acids and prenatal brain development in rats. $J$. Nutr., 104, 1002-1007.

26) Loizou, L. A. (1972): The postnatal ontogeny of monoamine-containing neurones in the central nervous system of the albino rat. Brain Res., 40, 395-418.

27) Sereni, F., Principi, N., Perletti, L., and Sereni, L. (1966): Undernutrition and the developing rat brain. Biol. Neonat. (Basal), 10, 254-265.

28) Porcher, W., and Heller, A. (1972): Regional development of catecholamine biosynthesis in rat brain. J. Neurochem., 19, 1917-1930.

29) Bacopoulos, N. G., and Bhatnagar, R. K. (1977): Correlation between tyrosine hydroxylase activity and catecholamine concentration or turnover in brain regions. $J$. Neurochem., 29, 639-643.

30) Schmidt, R. H., and Bhatnagar, R. K. (1979): Regional development of norepinephrine, dopamine- $\beta$-hydroxylase and tyrosine hydroxylase in the rat brain subsequent to neonatal treatment with subcutaneous 6-hydroxydopamine. Brain Res., 166, 293-308. 